\title{
THE AMERICAN INSTITUTE OF ELECTRICAL ENGINEERS.
}

New York, October 17, 1894.

The 90th meeting of the Institute was held this date at 12 West 31st Street, and was called to order at 8 P. M. by President Houston.

The Secretary read the minutes of the meeting of September 19th, which upon motion were approved.

The President :-The Secretary will please read the names of those who have been elected associate members at the meeting of Council to-day.

The Secretary read the following list:-

\begin{tabular}{|c|c|}
\hline CoLE, JoHN R., & $\begin{array}{l}\text { Address. } \\
\text { Sales Agent, New York Insulated } \\
\text { Wire Co., } 102 \text { Sucramento St., } \\
\text { San Francisco, Cal. }\end{array}$ \\
\hline Davis, Harold McGill, & $\begin{array}{l}\text { Advertising Manager, Electric H } \\
\text { Power, } 36 \text { Cortlandt St., N. Y.; } \\
\text { residence, 212 Clinton St., } \\
\text { Brooklyn, N. Y. }\end{array}$ \\
\hline Dommerque, Franz J., & $\begin{array}{l}\text { Chief Draughtsman, Chicago } \\
\text { Telephone Co.; residence, } 71 \\
\text { Potomac Ave., Chicago, Ill. }\end{array}$ \\
\hline Duncan, Thomas, & $\begin{array}{l}\text { Electrician, Laboratory Fort } \\
\text { Wayne Electric Corporation, } \\
407 \text { Broadway, Fort Wayne, } \\
\text { Ind. }\end{array}$ \\
\hline Dunn, Krngsley G., & $\begin{array}{l}\text { Electrician, Palace Hotel, } \\
\text { San. Francisco, Cal. }\end{array}$ \\
\hline
\end{tabular}

Etheridge, Chas. Locke, Chicago Telephone Co.; résidence, 4714 Kenwood Ave., Chicago, Ill.

Endorsed by. Geo. P Low. F. C. Colville. Sidney Sprout. dvertising Manager, Electric H. L. R. Emmet. Power, 36 Cortlandt St., N. Y.; H. A. Foster. Joseph Sachs.

C. H. Wilson. A. V. Abbott. A. S. Hibbard. F. S. Hunting. E. A. Barnes. C. S. Bradley.

Sidney Sprout. Geo P. Low. Wynn Meredith. R. H: Pierce. A. V. Abbott. A. S. Hibbard.

ErRe, M. K.,

Assistant to Manager of Lamp Sales, General Electric Co., Harrison, N. J.; residence, 4ะ S. Washington Sq., New York.

Ford, JAMes S.,

Electrician, Chicago Telephone Co.. Engineering Department, Chicago, 111.

C. H. Wilson.

A. V. Alibott.

A. S. Hibbard.

W. D. Weaver. Henry W. Frye. 
Hadley, Arthur L.,

Jones, Arthur W.,

Keller, Chas. L.,

Larned, Sherwood J.,

Noxon, C. Per Lee,

O'ConNeli, J. J.,

Olivetrit, Camillo,

Rhodes S. ARTHUi,

Roylance, L. St. D.,

SACKETT, WARD M.,

SANDERSON, EDWIN N.,

Slater, Frederick R.,

Strauss, Herman A.,

Total, 21.
Assistant Electrician to Chief Electrician and Gen'l Sup't, Fort Wayne Electric Corporation, 149 Griffith St., Fort Wayne, Ind.

Representative for So. Africa, John W. Kirkland. General Electric Co., Port Maurice Oudin. Elizabeth, So. Africa.

Theodore Stebbins.

Chicago Telephone Co. Chicago, Ill.

C. H. Wilson,

A. V. Abbott. A. S. Hibbard.

Electrical Engineer, Chicago Telephone Co., 20:3 Washington St., Chicago, Ill.

C. H. Wilson.

A. V. Abbott. A. S. Hibbard.

Contracting Electrical Engineer, 6.8 Mission St San Francisco, Cal.

Telephone Engineer, Chicago Telephone $\mathrm{Co}$; residence, 76 Eugene St., Chicago, Ill.

Geo. P. Low, Sidney Sprout, F. C. Colville.

C. H. Wilson. A. V. Abbott. A. S. Hibbard

Ingegnere Industriale, Ivrea, Wm. J. Hammer. Italy.

R. N. Baylis

Ralph W. Pope.

Electrician, Chief Testing Dep't, Chicago Telephone Co., Chicago, Ill.; residence, $429 \mathrm{~N}$. Pine Ave., Austin, Ill.

Electrical Engineer, with W. T. Brown, 2636 Howard St., San Francisco, Cal.

C. H. Willson.

A. V. Abbott. A. S. Hibbard.

Geo. P. Low. Sidney Sprout.

Assistant Chief Draughtsman, Chicago Telephone Co., residence, 3249 Groveland Are. Chisamgo, Ill.

New England Manager, Westing. house Electric Mfg. Co, 620 Atlantic A ve., Boston, Mass.; residence, Newton Centre, Mass.

Assistant Superintendent of Frederick Bedell. Buildings and Grounds, Colum- Harris J. Ryan. bia College; residence, $113 \mathrm{~W}$. C. P. Matthews. 48 th St., N. Y. City.

Electrical Engineer. Westing- Philip A. Langé. honse Electric \& Mfg. Co., 29 Chas. F. Scott. Plane St.; residence, 10 Clay 0. B. ShallenSt., Newark, N. J.
C. H. Wilson.

A. V. Abbott. A. S. Hibbard

F. B. H. Paine W. K. Archloold C. A. Terry. O. B. Shall

In the absence of the author the Secretary announced the title of the first paper before the meeting upon "The Theory" of Two and Three-Phase Motors," by Lieut. Samuel Reber, of Fort Riley, Kan. 


\section{THEORY OF TWO AND THREE PHASE MOTORS.}

BY LIEUT. SAMUEL REBER.

The complete mathematical solution of the two and three phase motors with the coefficients of self-induction as variables, and the effect of magnetic leakage taken account of,is extremely difficult, if not impossible. But an approximate solution in which the change of magnetic properties of the iron and magnetic leakage are neglected, the coefficients of self-induction considered constant, while the mutual-induction between the armature and field circuits follows a sine law, and the field supposed to be without projecting pole-pieces, is quite oasy. We will then proceed to the solution with these assumptions, remarking that the two-phase formulæ are those of Professor H. A. Rowland, while the three phase formulæ and tables are our own.

Use the following notation:

$L \ldots$... Coeflicient of self-induction of one armature circuit.

$L^{\prime} \ldots$. Coefficient of self-induction of one field circuit.

$e^{\prime} e^{\prime \prime} e^{\prime \prime \prime}$ Field currents.

$c, c_{11} c_{1 /}$ Armature currents.

E..... Maximum E. м. F. applied to field circuit.

$p$ and $p^{\prime}$ are Maxwell's electro-kinetic momenta of one armature and one field circuit.

b .... $2 \pi$ times the complete periods of field circuit.

$f \ldots \ldots 2 \pi$ times the complete periods of armature cirenit.

$\vartheta \ldots$ Angular position of the armature.

$M$..... Maximum value of coefficient of mutual-induction between a field and an armature circuit.

V..... Velocity of rotating field

$v \ldots$. Velocity of rotating armature. 
$\lambda \ldots$ Length of one complete wave of magnetization or angular distance subtended by four (or six in the case of three-phase) poles.

$I$..... Impedance of one armature circuit.

$I^{\prime} \ldots$ Impedance of field circuit.

$C c \ldots$ Maximum currents in one field and armature circuit. $R R^{\prime} \ldots$. Armature and field resistance.

$\phi$ and $\varphi$. Lag in the two circuits.

We may write at once the following equations:

$$
\begin{array}{ll}
\text { Two-phase. } & \multicolumn{1}{c}{\text { Three-phase. }} \\
c^{\prime}=C \cos (b t+\varphi) . & c^{\prime}=C \cos (b t+\phi) . \\
c^{\prime}=C \sin (b t+\phi) . & c^{\prime \prime}=C \cos (b t+\phi+120) . \\
c_{1}=c \cos (f t+\varphi) . & c^{\prime \prime \prime}=C \cos (b t+\phi+240) . \\
c_{n}=c \sin (f t+\varphi) . & c_{1}=c \cos (f t+\varphi) . \\
& c_{d \prime}=c \cos (f t+\varphi+120) . \\
& c_{u \prime}=c \cos (f t+\varphi+240) .
\end{array}
$$

The angular position of the armature at any moment will be $\alpha \vartheta$ where $\alpha=\frac{2 \tau}{\lambda}$, and in the case of the two-phase motor the mutual-induction between one armature circuit and the two field circuits adjacent will be $M \cos \alpha \vartheta$ and $M \sin \alpha \vartheta$, and for the other armature circuit will be $-M \sin \alpha \vartheta$ and $M \cos \alpha \vartheta$. For the three phase they are $M \cos \alpha \vartheta, M \sin (150-\alpha \vartheta), M \sin$ $(210-\alpha \vartheta)$, and $M \cos (\alpha \vartheta+120), M \sin (210-\alpha \vartheta), M \sin$ $(270-\alpha \vartheta)$.

For $p$ and $p^{\prime}$ we have for the two-phase

$$
\begin{aligned}
& p=L c_{1}+M c^{\prime} \cos \alpha \vartheta+M c^{\prime \prime} \sin \alpha \vartheta, \\
& p^{\prime} \quad L^{\prime} c^{\prime}+M c_{,} \cos \alpha \vartheta-M c_{\mu \prime} \sin \alpha \vartheta \text {, }
\end{aligned}
$$

substituting and reducing since $b t-f t=\alpha \vartheta$.

$$
\begin{aligned}
& p=L c \cos (f t+\varphi)+M C \cos (f t+\phi), \\
& p^{\prime}=L^{\prime} C \cos (b t+\phi)+M c \cos (b t+\varphi) .
\end{aligned}
$$

For the three-phase

$$
\begin{aligned}
& p=L c \cos (f t+\varphi)+\frac{3}{2} M C \cos (f t+\phi), \\
& p^{\prime}=L C \cos (b t+\phi)+\frac{3}{2} M c \cos (b t+\varphi) .
\end{aligned}
$$

For the two-phase motor, the equations for the other two circuits are the same as the first, except sine is substituted for cosine. In the three-phase the values will differ by 120 degrees in the cosine functions. Passing to the exponential form, and in the two-phase system multiplying the sine values by $i$, the imaginary unit, and adding, Maxwell's equations become 
1894.] REBER ON TWO AND THREE PIIASE MOTORS.

$$
\begin{gathered}
R c^{i(f t+\varphi)}+\frac{d p}{d t}=0 . \\
R^{\prime} C \varepsilon^{i(b t+\phi)}+\frac{d p^{\prime}}{d t}=E \varepsilon^{i b t} .
\end{gathered}
$$

If a condenser of capacity $q$ be added in series to the armature circuit, $L$ will be changed to $L-\frac{1}{f^{2} q}$.

Substituting, differentiating and reducing equations (1) and (2) for the two-phase reduce to

$$
\begin{gathered}
{\left[R+i\left(L f-\frac{1}{f^{2} q}\right)\right] \varepsilon^{i \varphi}+i f M \frac{C}{c} \varepsilon^{i \phi}=0 .} \\
\left(R^{\prime}+i b L^{\prime}\right) \varepsilon+i \phi b \frac{c}{C} \varepsilon^{i \varphi}=\frac{E}{C}
\end{gathered}
$$

divide (3) by $\varepsilon^{i} \varphi$ and reduce we have

$$
\varepsilon^{i(\psi-\varphi)}=\frac{c}{2 f M C}\left[R+2\left(L f-\frac{1}{f q}\right)\right]
$$

since $\varepsilon^{i(\psi-\varphi)}=\cos (\psi-\varphi) t+\sin (\psi-\varphi)$ we have at once

$$
\begin{aligned}
& \cos (\phi-\varphi)=-\left(L f-\frac{1}{f^{\prime} q}\right) \frac{c}{M f^{\prime} C} \\
& \sin (\psi-\varphi)=R \frac{c}{M f C}, \\
& \tan (\psi-\varphi)=-\frac{R}{L f-\frac{1}{f q}} .
\end{aligned}
$$

Squaring and adding (5) and (6) and reducing, we may write

$$
\frac{c}{C}=\frac{M f}{\sqrt{R^{2}+\left(L f-\frac{1}{f q}\right)^{2}}}=\frac{M f}{I}
$$

Eliminating $\varepsilon$ from (3) and (4), and writing

$$
\begin{gathered}
R R^{\prime}+b f\left[M^{2}-L^{\prime}\left(L-\frac{1}{f^{2} q}\right)\right]=A \\
b L^{\prime} R+f R^{\prime}\left(L-\frac{1}{f^{2} q}\right)=B
\end{gathered}
$$


we have

hence,

$$
E^{i \varphi}=\frac{-\frac{E}{C} I(B+i A)}{A^{2}+B^{i}}
$$

$$
\begin{aligned}
\sin \varphi & =\frac{-\frac{E}{C} A I}{A^{2}+B^{2}}=-\frac{A}{\sqrt{A^{2}+B^{2}}}, \\
\cos \varphi & =\frac{-\frac{E}{C} B I}{A^{2}+B^{2}}=-\frac{B}{\sqrt{A^{2}+B^{2}}}, \\
\tan \varphi & =\frac{A}{B} .
\end{aligned}
$$

Squaring (10) and (11), and adding and reducing

$$
\frac{E}{C}=\frac{\sqrt{A^{2}+B^{2}}}{I}
$$

Solving (5) and (6) by aid of (10) and (11)

$$
\begin{aligned}
& \sin \psi=\frac{A f\left(L-\frac{1}{f^{2} q}\right)-B R}{I \sqrt{A^{2}+B^{2}},} \\
& \cos \phi=\frac{A R+\left(L f-\frac{1}{f}\right) B f}{I \sqrt{A^{2}+B^{2}}} \\
& \tan \psi=\frac{A f\left(L-\frac{1}{f^{2} q}\right)-B R}{A R+f B\left(L-\frac{1}{f^{2} q}\right)} .
\end{aligned}
$$

For the three-phase by the sam̄e method of solntion

$$
\begin{aligned}
& \sin (\phi-\varphi)=\frac{2 c R}{3 C M f}=\frac{R}{I} . \\
& \cos (\psi-\varphi)=\frac{-2 c}{3 C M f}\left(L f-\frac{1}{f q}\right), \\
& \tan (\psi-\varphi)=-\frac{R}{L f-\frac{1}{f q}} . \\
& \frac{c}{C}=\frac{3 M f}{2 \sqrt{R^{2}-\left(L f-\frac{1}{f q}\right)^{2}}}=\frac{3 M f}{2 I}
\end{aligned}
$$




$$
\begin{aligned}
& A=R R^{\prime}+b t\left[\frac{9 M^{2}}{4}-L^{\prime}\left(L-\frac{1}{f^{2} q}\right)\right] \\
& B=b L^{\prime} R+f R^{\prime}\left(L-\frac{1}{f^{2} q}\right) \text {. } \\
& \sin \varphi=-\frac{\frac{E}{C} A I}{A^{2}+B^{2}}=-\frac{A}{\sqrt{A^{2}+B^{2}}} \\
& \cos \varphi=-\frac{\frac{E}{C} B I}{\sqrt{A^{2}+B^{2}}}=-\frac{B}{\sqrt{A^{2}+B^{2}}} \\
& \tan \varphi=\frac{A}{\bar{B}} \text {. } \\
& \frac{E}{C}=\frac{\sqrt{A^{2}+B^{2}}}{I} . \\
& \sin \phi=\frac{A f\left(L-\frac{1}{f^{2} q}\right) B R}{I \sqrt{A^{2}+B^{2}}} . \\
& \cos \psi=\frac{A R+B f\left(L-\frac{1}{f^{2} q}\right),}{I \sqrt{A^{2}+B^{2}}} \\
& \tan \phi=\frac{A f\left(L-\frac{1}{f^{2} q}\right)-B R}{A R+B f\left(L-\frac{1}{f^{2} q}\right)} .
\end{aligned}
$$

In the case of the two-phase motor the total work done on the motor will be

$$
\begin{aligned}
E C \cos \psi=E^{2} \frac{A R+B f\left(L-\frac{1}{f^{2} q}\right)}{A^{2}+B^{2}} \\
=C^{2} \frac{A R+B+\left(L-\frac{1}{f^{2} q}\right)}{I^{2}}
\end{aligned}
$$

The current heating in the field circuits is

$$
\begin{aligned}
\frac{C^{2} R^{\prime}}{\frac{\pi}{b}} \int_{\frac{\pi}{b}}^{0} \sin 2 b t+\frac{C^{2} R^{\prime}}{\frac{\pi}{b}} \int_{-\frac{\pi}{2 b}}^{\frac{\pi}{2 b}} \cos ^{2 b} t \\
=\frac{1}{2} C^{2} R^{\prime}+\frac{1}{2} C^{2} R^{\prime}=C^{2} R^{\prime}
\end{aligned}
$$


Likewise for the armature circuits the heating is $C^{2} R$.

$$
\begin{aligned}
C^{2} R^{\prime}+c^{2} R=C^{2}\left(\frac{R M^{2} f^{2}+R^{\prime} I^{2}}{I^{2}}\right) \\
=E^{2}\left(\frac{R M^{2} f^{2}+R^{\prime} I^{2}}{A^{2}+B^{2}}\right)
\end{aligned}
$$

The total energy transformed into mechanical work less the hysteresis loss in the fields is:

$$
\begin{aligned}
E C \cos \psi-\left(c^{2} R+C^{2} R^{\prime}\right)=E^{2} \frac{R M^{2} f(b-f)}{A^{2}+B^{2}} \\
=C^{2} \frac{R M^{2} f(b-f)}{I^{2}}
\end{aligned}
$$

The ratio of this to the $c^{2} R$ loss of the armature is $\frac{b-f}{f}$ (when no condenser is used) or $\frac{v}{V-v}$, hence the armature efficiency is $\frac{v}{V}$, when hysteresis loss in the field is neglected.

In the three-phase motor the work done by the currents on the motor is :

$$
\begin{aligned}
\frac{3}{2} E C \cos \psi=\frac{3}{2} E \frac{A R+B f\left(L-\frac{1}{f^{2} q}\right)}{A^{2}+B^{2}} \\
=\frac{3}{2} C^{2} \frac{A R+B f\left(L-\frac{1}{f^{2} q}\right)}{I^{2}}
\end{aligned}
$$

The current heating is :

$$
\begin{array}{r}
\frac{3}{2}\left(e^{2} R+C^{2} R^{\prime}\right)=\frac{3}{8} C^{2}\left(\frac{9 M^{2} f^{2} R+4 R^{\prime} I^{2}}{I^{2}}\right) \\
=\frac{3 E^{2}}{8}\left(\frac{9 M^{2} f^{2} R+4 R^{\prime} I^{2}}{A^{2}+B^{2}}\right)
\end{array}
$$

The total energy transformed in the armature less the hysteresis loss in the fields is :

$\frac{3}{2} E \cos \psi-\frac{3}{2}\left(c^{2} R+C^{2} R^{\prime}\right)$

$$
=\frac{27}{8} E^{2} \frac{R M^{2} f(b-f}{A^{2}+B^{2}}=\frac{27}{8} C^{2} \frac{R M f(b-f)}{I^{2}}
$$

and the ratio of this to the $c^{2} R$ loss in the armature is as: before $\frac{b-f}{f}$. 
The angular torque is equal to the work divided by the velocity, and is in the case of the two-phase motor

$$
E^{2} \frac{2 \pi}{\lambda} \frac{R M^{2} f}{A^{2}+B^{2}}=C^{2} \frac{2 \pi}{\lambda} \frac{R M^{2} f}{I^{2}}
$$

and for the three-phase

$$
\frac{27}{8} \frac{2 \pi}{\lambda} E^{2} \frac{R M^{2} f}{A^{2}+B^{2}}=\frac{27}{8} C^{2} \frac{2 \pi}{\lambda} \frac{R M^{2} f}{I^{2}} .
$$

The starting torque can be increased by changing either the resistance or condenser; representing the quantities as starting by the sub $o$, we have the ratio of the starting torque to the running torque as follows for both cases:

$$
\frac{T_{\mathrm{o}}}{T}=\frac{E_{\mathrm{o}}^{2} R_{\mathrm{o}} b\left(A^{2}+B^{2}\right)}{E^{2} R^{2} f\left(A_{\mathrm{o}}^{2}+B_{\mathrm{o}}^{2}\right)}=\frac{C_{\mathrm{o}}^{2} R_{0} b I^{2}}{E^{2} R^{2} f I^{2}} .
$$

At a certain speed the torque is a maximum, and the motor, if pushed in its work beyond this speed will stop. To prevent this, the motor should not be pushed to a point more than half the maximum torque. This speed will be given by finding what value of $f$ will make $T$ a maximum, and there will be two solutions depending on whether $E$ or $C$ is constant. To simplify the solution make the following abbreviations :

$$
\begin{gathered}
l=L-\frac{1}{f^{2} q} \quad l_{0}=L-\frac{1}{b^{2} q}, \\
K=\frac{R}{l f} \quad K_{\mathrm{o}}=\frac{R_{\mathrm{o}}}{l b} \quad m^{2}=\frac{M^{2}}{l L^{\prime}} \quad K_{\mathrm{o}}^{\prime}=K^{\prime}=\frac{R^{\prime}}{b L^{\prime}},
\end{gathered}
$$

then

$$
\begin{gathered}
A^{2}+B^{2}=b^{2} f^{2} l^{2} L^{2}\left[\left(K K^{\prime}-1+m^{2}\right)^{2}+K^{2}+K^{\prime 2}\right] \\
I^{2}=l^{2} f^{2}\left(K^{2}+1\right) . \\
I_{0}^{2}=l^{2} f^{2}\left(K_{\mathrm{o}}^{2}+1\right) . \\
T=\frac{2 \pi}{\lambda} C^{2} \frac{M^{2}}{l} \frac{K}{K^{2}+1} \\
=\frac{2 \pi}{\lambda} E^{2} \frac{K m^{2}}{b^{2} L^{\prime}\left[\left(K K^{\prime}-1+m^{2}\right)^{2}+K^{2}+K^{\prime 2}\right]^{\circ}} \\
W(\text { work })=C^{2} \frac{K M^{2}(b-f)}{l\left(K^{2}+1\right)} R m^{2} \\
=E^{2} \frac{b-f}{L^{\prime}\left[\left(K K^{\prime}-1+m^{2}\right)^{2}+K^{2}+K^{\prime 2}\right]}
\end{gathered}
$$

For the three-phase the same solution, except $m^{2}=\frac{9 M^{2}}{4 l L^{\prime}}$, 
the torque reduces to this form

$$
\begin{aligned}
\frac{27}{8} \frac{2 \pi}{\lambda} & C^{2} \frac{M^{2}}{l} \frac{K}{K^{2}+1} \\
& =\frac{27}{8} \frac{2 \pi}{\lambda} E^{2} \frac{K m^{2}}{b^{2} L^{\prime}\left[\left(K K^{\prime}-1+m^{2}\right)^{2}+K^{2}+K^{\prime 2}\right]} .
\end{aligned}
$$

It is evident from the similarity of the formulæ that the two and three phase motors have the same properties and differ only in the constants, hence what follows will apply to both kinds of motors.

\section{Constant Ourrents.}

$T$ is a maximum when

$$
f^{2}=\frac{R^{2}}{2 L^{2}}-\frac{1}{L q} \pm \sqrt{\frac{3}{L^{2} q^{2}}+\left(\frac{1}{L q}-\frac{R^{2}}{2 L^{2}}\right)^{2}}
$$

If there is no condenser we have at once the condition for maximum torque

$$
R=f L \text {. }
$$

Consequently the armature resistance must be adjusted till the condition is fulfilled to obtain the maximum torque. The maximum torque can be obtained at starting by a proper resistance, as at starting $f=b$. The armature velocity for maximum torque in terms of the rotating field velocity is :

$$
V\left(1-\frac{1}{b} \sqrt{\frac{R^{2}}{2 L^{2}}-\frac{1}{L q} \pm \sqrt{\left.\frac{1}{R q^{2}}-\frac{1}{L q}-\frac{R^{2}}{2 L^{2}}\right)^{2}}}\right.
$$

When $b L-R=0$ the torque is a maximum at the start and will decrease rapidly as the speed increases, likewise when $b L<R$ the torque at the start is greatest and will decrease rapidly as the speed goes up. Such motors will start well, will have a low efficiency and will regulate poorly as the decrease of torque will increase if speed is too slow. When $b L>R$ the point of maximum torque comes near the point of maximum speed, giving good regulation but they will have poor starting qualities unless resistance is introduced at the start and then cut out.

The maximum value of the torque when $f l=R$ is

for the two, and

$$
\frac{2 \pi}{\lambda} \frac{C^{2} M^{2}}{2 L}
$$

$$
\frac{27}{8} \frac{2 \pi}{\lambda} \frac{C^{2} M^{2}}{2 L}
$$


for the three-phase motors which is independent of the speed, and depends only on the proper adjustment of the armature resistance.

The equations of torque with no condenser reduce to

$$
T=\frac{2 \pi}{\lambda} C^{2} \frac{M^{2}}{l} \frac{K}{K^{2}+1}
$$

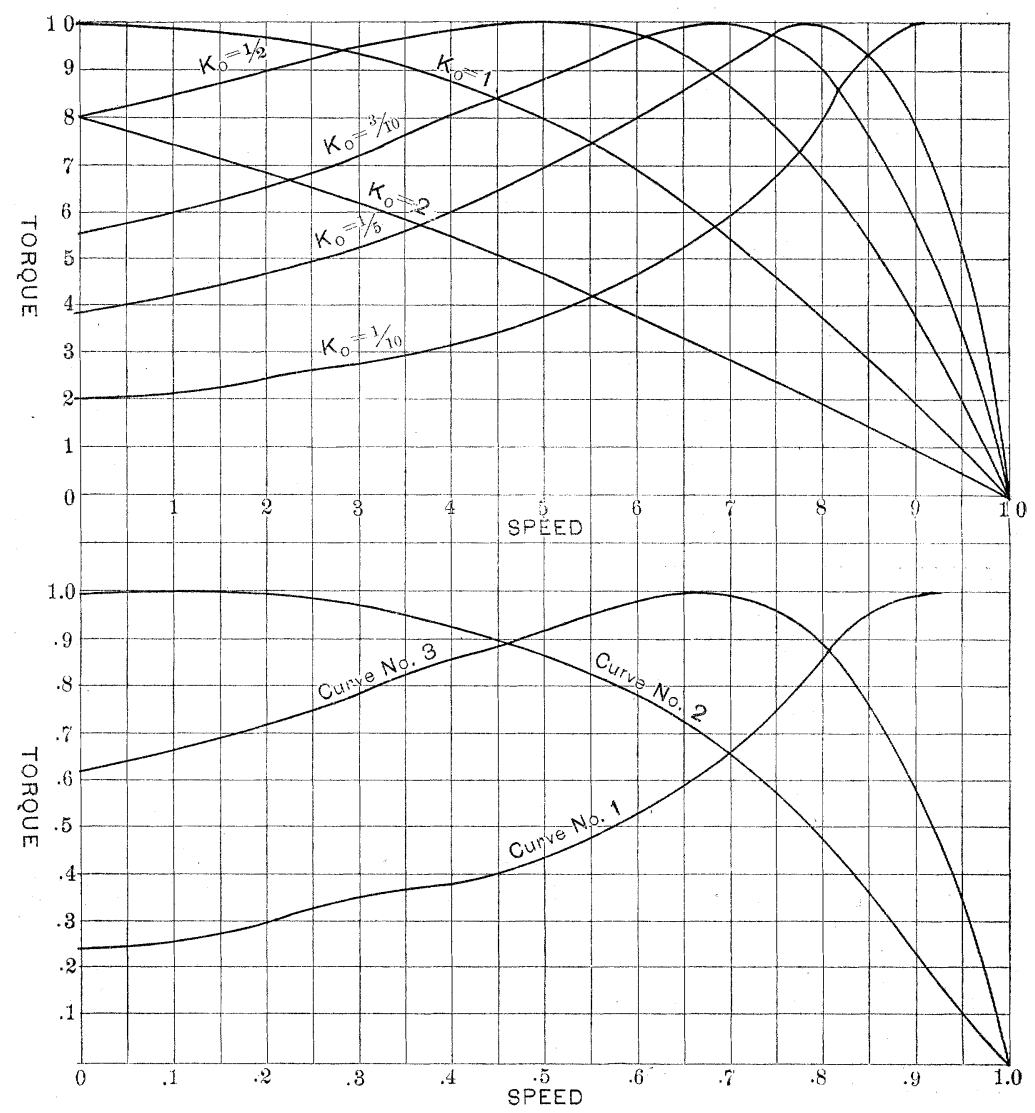

Fig. 1.

for the two-phase, and

$$
T=\frac{27}{8} \frac{2 \pi}{\lambda} C^{2} \frac{M^{2}}{l} \frac{K}{K^{2}+1}
$$

for the three-phase. The variable part of which is $\frac{K}{K^{2}+1}$ which may be put in the form 


$$
\frac{K_{\mathrm{o}}\left(1-\frac{v}{V}\right)}{K_{\mathrm{o}}^{2}+\left(1-\frac{v}{V}\right)^{2}}=\frac{1}{\frac{K_{\mathrm{o}}}{1-\frac{v}{V}}+\frac{1-\frac{v}{V}}{K_{\mathrm{o}}}}
$$

Representing the value of $V$ by unity, and expressing the torque in terms of the maximum as unity we have the following table:

TABLE I.

\begin{tabular}{|c|c|c|c|c|c|c|}
\hline $\begin{array}{l}v \\
V\end{array}$ & $\begin{array}{c}K_{0}=1 \\
T\end{array}$ & $\begin{array}{c}K_{0}=\frac{1}{2} \\
T .\end{array}$ & $\begin{array}{c}K_{0}=\frac{3}{10} \\
I .\end{array}$ & $\begin{array}{c}K_{0}=\frac{1}{5} \\
T\end{array}$ & $\begin{array}{c}K_{0}=\frac{1}{10} \\
T .\end{array}$ & $\begin{array}{c}K_{0}=2 \\
T .\end{array}$ \\
\hline $\begin{array}{r}0.0 \\
.1 \\
.2 \\
.3 \\
.4 \\
.5 \\
.6 \\
.7 \\
.8 \\
.9 \\
\text { r.0 }\end{array}$ & $\begin{array}{r}\text { x.00 } \\
.99 \\
.98 \\
.04 \\
.88 \\
.80 \\
.69 \\
.55 \\
.38 \\
.20 \\
.00\end{array}$ & $\begin{array}{r}.80 \\
.85 \\
.90 \\
.95 \\
.98 \\
x .0 \\
.98 \\
.88 \\
.69 \\
.38 \\
.00\end{array}$ & $\begin{array}{r}.55 \\
.60 \\
.66 \\
.72 \\
.80 \\
.88 \\
.96 \\
. .0 \\
.92 \\
.60 \\
.00\end{array}$ & $\begin{array}{c}.38 \\
.42 \\
.47 \\
.53 \\
.60 \\
.69 \\
.80 \\
.92 \\
\mathrm{r.0} \\
.80 \\
.0\end{array}$ & $\begin{array}{c}.20 \\
.22 \\
.25 \\
.28 \\
.32 \\
.38 \\
.47 \\
.60 \\
.80 \\
\mathrm{r} .0 \\
.00\end{array}$ & $\begin{array}{l}.80 \\
.75 \\
.69 \\
.62 \\
.55 \\
.47 \\
.38 \\
.29 \\
.20 \\
.00 \\
.00\end{array}$ \\
\hline
\end{tabular}

Taking the safe working torque at .5 the maximum torque, the value of $\frac{v}{V}$ will be for the various values of $K_{\mathrm{o}}$ as follows:

$$
\begin{aligned}
& K_{\mathrm{o}}=2, \frac{v}{V}=.48 ; K_{\mathrm{o}}=1, \frac{v}{V}=.73 ; K_{\mathrm{o}}=\frac{1}{2}, \frac{v}{V}=.87 ; \\
& K_{\mathrm{o}}=\frac{3}{10}, \frac{v}{\nabla}=.92 ; K_{\mathrm{o}}=\frac{1}{5}, \frac{v}{V}=.94 ; K_{\mathrm{o}}=\frac{1}{10}, \frac{v}{V}=.97 .
\end{aligned}
$$

The ratio $\frac{v}{V}$ likewise gives the armature efficiency and consequently $K_{\mathrm{o}}$ should be as small as possible, and ought not to be greater than about $\frac{3}{10}$; even in small motors. The diagram shows the necessity of a starting resistance in high efficiency motors and the way they regulate. Fig. 2 shows some curves of three-phase motors built by Steinmetz, and described by him in the March Transactions of this year.

If the condition of maximum torque is satisfied, the ratio of starting to working torque with constant current does not depend on the frequency, but only on the working out-put which can only be increased by change of size and not design. 
If the motor is forced beyond the point of maximum torque it is not only liable to stop, but to make the starting torque by comparison smaller. For a given current the maximum torque and work depend on the ratio of $\frac{M^{2}}{L}$. If there is no magnetic

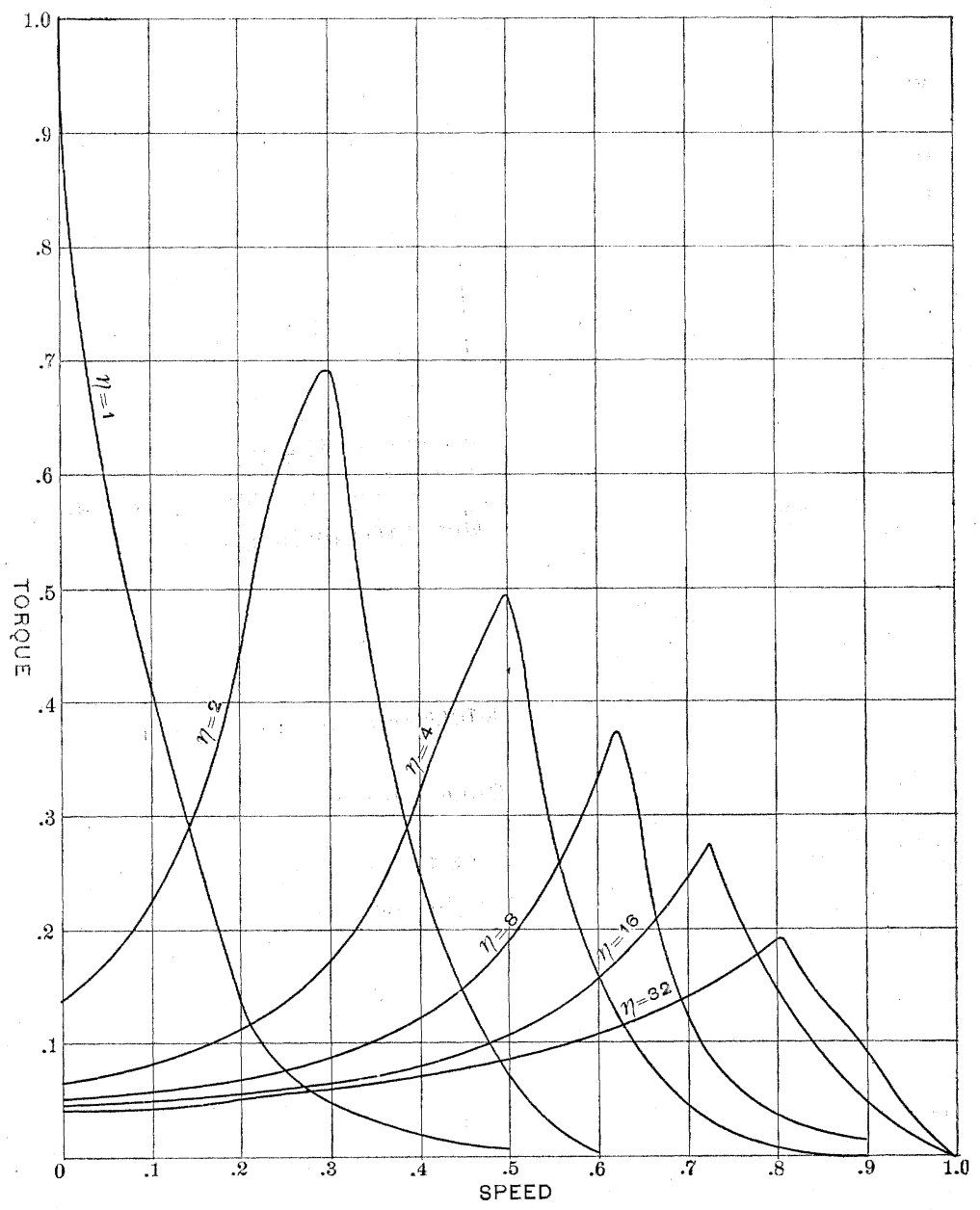

FIG. 2.

leakage $M^{2}=L L^{\prime \prime}, L^{\prime \prime}$ being that part of the field self-induction interior to the machine, $L$ therefore cannot be diminished without decreasing the output or increasing $L^{\prime \prime}$ at the same time. If the field be increased, the same output can be obtained with a smaller value of $L$, but this increases the electromotive- 
force and does not change the properties, as these depend on the ratio $K$, and not on the self.induction and resistance alone. If there is leakage as there always is, $M^{2}<L L^{\prime \prime}$ which reduces the output.

\section{Condenser in Armature Circuit.}

The ratio of the torque of a motor with a condenser in the armature to one without, is

$$
\frac{R^{2}+L^{2} f^{2}}{R^{2}+f^{2}\left(L-\frac{1}{f^{2} q}\right)^{2}}
$$

whose maximum value is $1+\frac{1}{K^{2}}$. This maximum by proper adjustment of the condenser can be thrown at any value of the armature velocity. The value of $f$ which makes the above ratio a maximum is $f^{2}=\frac{1}{2 L q}\left(1+\sqrt{2} R^{2} L^{2} q+L^{2}\right)$, hence by

TABLE II.

\begin{tabular}{|c|c|c|c|c|c|c|}
\hline $\begin{array}{l}v \\
V\end{array}$ & $n=1$ & $n=2$ & $n=4$ & $\begin{array}{c}K_{0}=\frac{1}{5} \\
n=8\end{array}$ & $n=16$ & $n=32$ \\
\hline $\begin{array}{r}0.0 \\
.1 \\
.2 \\
.3 \\
.4 \\
.5 \\
.6 \\
.7 \\
.8 \\
.9 \\
1.0\end{array}$ & $\begin{array}{c}\text { I0.00 } \\
4.21 \\
\mathrm{I} .32 \\
.48 \\
.20 \\
.09 \\
.04 \\
.01 \\
.003 \\
.0004 \\
.000\end{array}$ & $\begin{array}{l}\mathbf{r} .37 \\
2.25 \\
4.54 \\
6.95 \\
2.48 \\
.70 \\
.2 \mathrm{x} \\
.05 \\
.0 \mathrm{x} \\
.006 \\
.000\end{array}$ & $\begin{array}{r}.66 \\
.83 \\
1.15 \\
x .77 \\
3.24 \\
5.06 \\
1.76 \\
.47 \\
.07 \\
.03 \\
.00\end{array}$ & $\begin{array}{r}.49 \\
.57 \\
.70 \\
.90 \\
.23 \\
1.95 \\
3.36 \\
2.24 \\
.36 \\
.12 \\
.000\end{array}$ & $\begin{array}{r}.43 \\
.49 \\
.57 \\
.67 \\
.83 \\
\mathrm{r.10} \\
\mathrm{x} .6 \mathrm{r} \\
2.47 \\
\mathrm{x} .52 \\
.46 \\
.00\end{array}$ & $\begin{array}{c}.40 \\
.4 \mathrm{I} \\
.52 \\
.59 \\
.69 \\
.88 \\
1 . \mathrm{II} \\
\mathrm{I} .54 \\
\mathrm{I} .9 \mathrm{I} \\
.92 \\
.000\end{array}$ \\
\hline
\end{tabular}

adjusting the value of $q, f$ can be made anything we please.

Calling the maximum starting torque without a condenser $l$, the starting torque with a condenser is

$$
\frac{2 b L R}{R^{2}+f^{2}\left(L-\frac{1}{f^{2} q}\right)^{2}}
$$

times as great, and will be a maximum when $L=\frac{1}{f^{2} q}$ which reduces the factor to $\frac{2}{K_{0}}$. This can have a large value if the resistance of the armature is small. Thus we see that the starting torque can be increased without changing the resistance, and 
this increase of torque is obtained, not by increasing the current in the field circuits, but only in the armature. When the condition $L=\frac{1}{b^{2} q}$ is satisfied, the torque at any velocity with a condenser is using the same unit as before

$$
\frac{2 K}{K^{2}+\left(1-\frac{b^{2}}{f^{2}}\right)^{2}}
$$

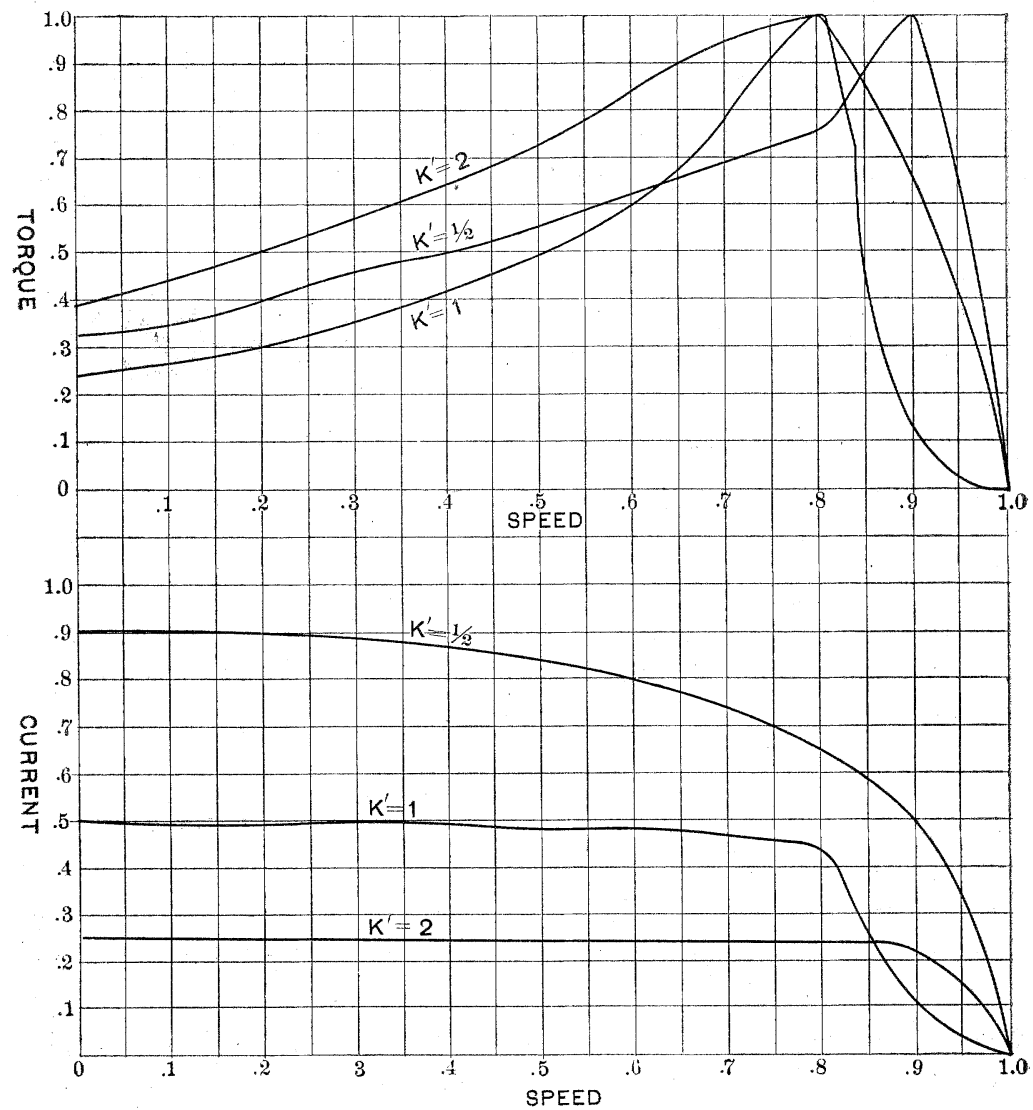

Fig. 3.

where

and

$$
K=K_{\mathrm{o}} \frac{v}{V-v}
$$

$$
\frac{b^{2}}{f^{2}}=\frac{v^{2}}{(V-v)^{2}}
$$


To illustrate, let us take the case where $K_{\mathrm{o}}=\frac{1}{5}$, and compare it with the same case without a condenser, the general formula in writing for $q, \frac{n}{b^{2} L}$ is

$$
\frac{2 K}{K^{2}+\left(1-\frac{1}{n} \frac{b^{2}}{f^{2}}\right)^{2}}
$$

Table II. is calculated by this formula.

The curves show that the condenser has only a local effect on the torque and a small change in velocity renders it useless, though this defect could be overcome by a variable condenser. The advantage is that the motor can be run at a slow speed with increased torque without overheating. As the field current has

TABLE III.

\begin{tabular}{|c|c|c|c|c|c|c|}
\hline \multirow{2}{*}{$\begin{array}{l}v \\
V\end{array}$} & \multicolumn{3}{|c|}{ CURRENT. } & \multicolumn{3}{|c|}{ TORQUE. } \\
\hline & $K^{\prime}=\frac{1}{2}$ & $K^{\prime}=1$ & $K^{\prime}=2$ & $K^{\prime}=\frac{1}{2}$ & $K^{\prime}=1$ & $K^{\prime}=2$ \\
\hline 0.0 & x.8I & x.०0 & .50 & .33 & .24 & .39 \\
\hline.$x$ & I.80 & .99 & .50 & .35 & .26 & .45 \\
\hline .2 & $\begin{array}{l}\text { I. } 78 \\
\end{array}$ & .99 & .50 & .40 & $\cdot 3 x$ & $.5 I$ \\
\hline$\cdot 3$ & $\begin{array}{l}\text { r. } 76 \\
\end{array}$ & .99 & $.5^{\circ}$ & .46 & $.3^{6}$ & .58 \\
\hline .4 & $\begin{array}{r}\text { r. } 73 . \\
x .64\end{array}$ & .98 & .50 & .50 & $.4 \mathrm{I}$ & .65 \\
\hline .5 & $\begin{array}{l}1.64 \\
r .58\end{array}$ & $\begin{array}{l}.97 \\
.97\end{array}$ & $\begin{array}{r}.50 \\
.50\end{array}$ & $\begin{array}{r}.56 \\
.60\end{array}$ & $\begin{array}{l}.50 \\
.60\end{array}$ & $\begin{array}{l}.74 \\
.85\end{array}$ \\
\hline & I. $4 \mathrm{I}$ & .94 & $\begin{array}{l}.49 \\
\end{array}$ & .65 & .79 & .94 \\
\hline .8 & $\mathrm{I} .22$ & .88 & .48 & .75 & 1.00 & 1.00 \\
\hline .9 & r.oo & .22 & .44 & I.00 & .10 & .66 \\
\hline I.O & 0,00 & .00 & . & .00 &.$\infty$ & .00 \\
\hline
\end{tabular}

been supposed to be constant there is no extra heating of the field circuits; this will require special means for keeping the field current constant. By use of a variable condenser the speed can be made to increase to any extent up to synchronism and there is no overheating at low speeds, or waste of power by the insertion of resistance to increase the torque. A variation of the capacity from one to four, changes the armature speed from zero to one-half of the rotating field velocity and an increase of condenser capacity to 25 varies the armature to 80 per cent. of synchronism at the point of maximum torque.

\section{Constant E. M. F.}

Neglecting the change of the magnetic properties of the iron at high magnetization, the torque and work of the motor vary at 
the square of the field current. With constant E. M. F., when the motor is at rest or just starting, the current is very large and if there are other motors or lamps in the exterior circuit, they are rendered unsteady at the moment of starting of the first motor, this however may be corrected by a secondary transformer. The formulie for the current and torque for $E$ constant are

$$
\begin{gathered}
C=\frac{E}{b L^{\prime}} \sqrt{\frac{K^{2}+1}{\left(K K^{\prime}-1+m^{2}\right)^{2}+K^{2}+K^{\prime 2}}} \\
T=E^{2} \frac{2 \pi}{\lambda} \frac{1}{b^{2} L^{\prime 2}} \frac{K m^{2}}{\left(K K^{\prime}-1+m^{2}\right)^{2}+K^{2}+K^{\prime 2}}
\end{gathered}
$$

for the two-phase, and

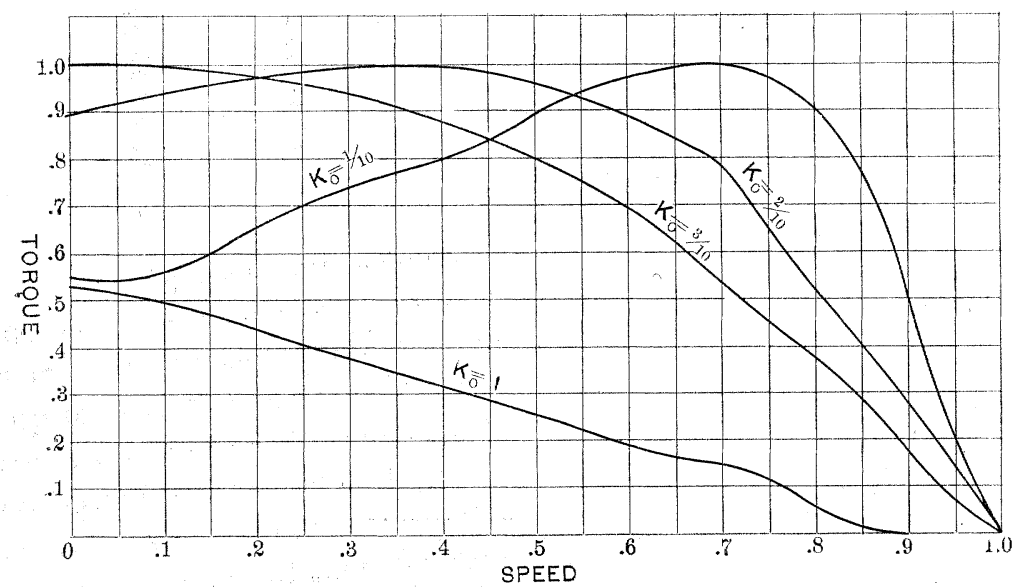

Fig. 4.

$$
T=\frac{27}{8} E^{2} \frac{2 \pi}{\lambda} \frac{1}{b^{2} L^{\prime 2}} \frac{K^{2}+1}{\left(K K^{\prime}-1+m^{2}\right)^{2}+K^{2}+K^{\prime 2}}
$$

for the three-phase.

To keep down the heating of the fields, the field resistance must be small, hence $K^{\prime}$ must be small compared with unity. When the self-induction external to the machine in the field circuit and the magnetic leakage are small, $m^{2}$ is very nearly equal to unity. There is always some self-induction in the dynamo or transformer so that $m^{2}$ is rarely less than $\frac{1}{2}$, for a transformer equal in self-induction to the motor $m^{2}=\frac{1}{2}$. If there is no condenser, the torque is a maximum for $K=\frac{K^{\prime 2}+\left(m^{2}-1\right)^{2}}{K^{\prime 2}+1}$, hence $K$ 
must vary from 0 to $\frac{1}{2}$, which gives $R$ varying from 0 to $\frac{1}{2} f L$. as the condition of maximum torque. The added starting resistance must be less than in the case of constant current.

Table III. and curves, show the variation of current in the field circuits and the torque when the field resistance is changed, but $K_{0}=\frac{1}{5}$ for the armature: $m_{2}$ is taken at .75 the torque is expressed in terms of the maximum as unity.

To show the effect of changing the armature resistance $I$ have taken the case where $K^{\prime}=.2 m^{2}=.75$ and calculated for $K_{0}=\frac{1}{10}, \frac{2}{10}, \frac{3}{10}$ and 1 . The value of $K_{0}=\frac{3}{10}$ gives the maximum at the start (see Table IV. and curves).

We may conclude that the two and three-phase motors have in general the same properties, and that the most important relation is that of $R$ to $f L$. The lower the field and armature

TABLE IV.

\begin{tabular}{|c|c|c|c|c|}
\hline $\begin{array}{l}v \\
V\end{array}$ & $K_{0}={ }_{10}^{1}$. & $K_{0}=\frac{2}{10}$ & $K_{0}=\frac{3}{10}$ & $K_{0}=1$ \\
\hline $\begin{array}{l}.0 \\
. I \\
.2 \\
.3 \\
.4 \\
.5 \\
.6 \\
.7 \\
.8 \\
.9 \\
. .0\end{array}$ & $\begin{array}{r}.55 \\
.56 \\
.65 \\
.74 \\
.80 \\
.89 \\
.97 \\
x .00 \\
.91 \\
.53 \\
.00\end{array}$ & $\begin{array}{r}.89 \\
.94 \\
.97 \\
.99 \\
1.00 \\
.95 \\
.89 \\
.74 \\
.53 \\
.28 \\
.00\end{array}$ & $\begin{array}{r}\mathrm{r} .00 \\
.99 \\
.98 \\
.95 \\
.88 \\
.80 \\
.70 \\
.54 \\
.37 \\
.17 \\
.00\end{array}$ & $\begin{array}{l}.53 \\
.5^{\circ} \\
.54 \\
.38 \\
.32 \\
.26 \\
.23 \\
.18 \\
.06 \\
.008 \\
.000\end{array}$ \\
\hline
\end{tabular}

resistance are, the higher the efficiency of the armature and the nearer to synchronism is the point of maximum torque. $\mathrm{We}$ see that high efficiency motors require a starting resistance, and that in such motors the torque can be readily regulated by adjustment of the armature resistance and we are enabled to throw the point of maximum torque at any speed we desire. It is likewise apparent that the smaller the magnetic leakage the more efficient the motor.

If the frequency is supposed to vary, the speed and output are greatly changed. $K_{0}$ varies inversely as the frequency, so the motor is improved for higher frequencies as far as this relation effects it. Increasing the frequency $n$ times in a motor without a condenser, the velocity will be increased $n$ times, $K_{0}$ decreased $n$ times, the maximum torque is not affected, while the hysteresis: 
is increased $n$ times nearly, the output of the motor will be increased nearly $n$ times if the motor is run at a given percentage of the maximum torque. Hence it is an advantage to increase the frequency till the hysteresis heating becomes too great, or the motor runs too fast. If the efficiency is to be kept constant, the work will then vary as $n^{2}$ and the field and armature currents will be increased $\sqrt{n}$ times. Hence increase in speed gives an advantage in output till the machines begins to overheat. With a condenser the same facts hold, but with this advantage that an increase in the frequency greatly reduces the size of condenser necessary. A high frequency motor will weigh less than a low frequency one. When the clearance is large, the advantage of high frequency motors is not so decided, and if very large the low frequency motors are better if weight is no consideration. The higher frequency motor will contain less iron and more copper. If we vary the size of the motor, keeping the magnetization constant, output and hysteresis vary directly as the weight; the heating of the field and armature circuits, directly as the increase of size. 


\section{Discussion.}

DR. M. I. PupIN :-Mr. President, I read with much pleasure this very interesting paper of Lientenant Reber, and, in the absence of the writer himself, I venture to present his case by a few remarks which are intended as an introduction into the discussion of the subject matter of this paper. I hope that the discussion itself will be taken up by others who have a better practical knowledge of the subject than I have.

One thing which struck me as particulary meritorions in this paper is the method by which the proposed problem is treated. The author states clearly the problem before him, namely, the theory of the two and three-phase induction motors, and the conditions for which he proposes to discuss the solution of the problem. He then proceeds from the very fountain-head of the solution of all problems of this class, namely, from Maxwell's equations, which are given on page 733 , under (1) and (2). A rather interesting aspect of Maxwell's equations (1) and (2) presents itself to my mind, and with your kind permission I shall mention it. They correspond to Newton's second law of motion in mechanics. This law states, as is well-known, that the rate at which the momentum of a moving body varies is equal to the effective force. Similarly, so Maxwell's equations tell us, that at which the electro-kinetic momentum of an electrical circuit varies, is equal to the effective electromotive force. The analogy is complete. One of the great merits of Maxwell's method of presentation is the strong emphasis of the analogy between the fundamental relations which underly the phenomena of electrical current and those of mechanical motion.

The electro-kinetic momentum of an electric circuit must, of course, be calculated first. This is done on page 732. There we have $p$, the electro-kinetic momentum of one of the armature circuits, and $p_{1}$ the electro-kinetic momentum of one of the field circuits. The electro-kinetic momentum is simply the total number of interlinkages of the magnetic lines of induction which the circuit has. The rate, then, at which these interlinkages vary, is equal to the impressed electromotive force, minus the passive resisting force due to ohmic resistance. This part of Lient. Reber's paper, though it occupies two pages only, is by far the most difficult, and the difficulties have been overcome by a method of the Maxwellian school. The remaining part contains the working out of the several details of the solution, and is necessarily moulded with due deference to practical considerations.

These considerations contain questions referring to the power, the efficiency, and the torque. These are the three most important elements in our study of the working of a motor, and to these lieut. Reber devotes his attention in the remaining part of his paper.

Now, to calculate the power we must know-in alternating currents-not only the current and the electromotive force cur- 
rent, but also the difference in phase between them. The impressed electromotive forces being given, we have to calculate from Maxwell's equations (1) and (2) the currents and the differences in the phase between the currents and the impressed electromotive forces. Lieut. Reber simplified the problem in the following way: he eliminated hysteresis, Foucault currents and magnetic leakage. That allowed him then to express the steady state of the currents by the same mathematical functions as the impressed electromotive force; that is simple harmonics given on p. 732 .

Next comes the calculation of the difference of phases between the currents and the impressed electromotive forces, which is done from equation (3) to (24). The power supplied to the motor is there calculated, and subtracting from this the value of heat losses gives the power transformed into mechanical power, which divided by the armature speed gives the torque, p. 736. Mechanical power obtained divided by electrical power supplied, gives the efficiency (p. 737).

The torque of an induction motor, and, for that matter, of any other motor, gives the practical engineer more anxiety than any other element. He is quite willing to sacrifice a considerable part of even the efficiency for the sake of the torque. Lieut. Reber does well to devote a very large portion of his paper to this side of the question. His method of investigating this point is very clear indeed. It is a priori evident that in an induction motor the torque at any moment will depend on the respective values of the currents in the armature and in the field, and also on the differences in the phases between them, that is practically on the phase of the armature current, hence, if we are to vary the torque for a given armature speed, we can do it by varying the phase of the armature current. That, it seems to me, is self-evident and needs no mathematical discussion.

Now there are only three ways by means of which we can vary the phase of the armature current; that is, the frequency of the armature current being given, we can vary the phase by varying one of the three fundamental quantities of the armature circuit, that is, capacity, self-induction, or resistance. A variation of the self-induction is out of the question as a simple consideration will show. Then there are left their resistance and capacity. The torque therefore, of an induction motor can be varied at any given speed, by varying the resistance of the armature or the electrostatic capacity. The phase depends on the ratio between the reactance and the resistance. Hence, if we choose to leave the reactance constant, the only thing to vary then is the resistance. If however, the armature circuit contains a condenser, then the reactance may be varied without varying the self-induction or the resistance. This ratio of reactance to resistance, must have a perfectly definite value if we are to have a maximum torque for a given speed. It is this ratio which the author calls $K$, and 
he points out very distinctly indeed that this quantity is one of the most important ones to consider, at any rate looking upon the motor in the light in which he proposed to regard it. $\mathrm{He}$ expresses then the power and the torque in terms of this quantity $K$, so that in order to bring out the conditions under which a given motor at a given speed will run with a given torque or give a certain power, he simply has to consider the variation of the torque with respect to this one variable $K$.

Two particular cases are considered. A constant current induction motor with one of two devices in it. A device for varying the resistance of the armature, and another for varying the electrostatic capacity, that is, a condenser in series with the armature.

The relation of reaction to resistance which will give the maximum torque at a given speed in a constant current motor is given on p. 738. If I understand correctly Dr. Bell's paper on induction motors, this resistance-varying device has been found practically to work quite satisfactorily. It is very curious to observe here that about nine or ten years ago, when Dr. John Hopkinson revived the question of running alternators in parallel, his theoretical deductions suggested that the best design for alternators intended to run in parallel will make the resistance of the alternators equal to the reactance, exactly the same relation which gives the maximum torque in induction motors. The theory of the induction motor throws a new light on the other question, that is to say, an alternator will run best in the parallel, at a given frequency when it exerts the maximum torque for a given difference of potential. The maximum torque is obtained with a condenser in the armature circuit when the armature circuit and the induced electromotive force are in resonance. The case of constant potential motors is then discussed in the same manner, and the results arrived at are similar to those just mentioned.

The whole theory here presented is, as I said, extremely simple. A great deal has been written upon this subject, especially by Professor Arnold, of Carlsruhe, who, I think, has published a book on the subject lately. But I must say the way in which Lieut. Reber has treated the question seems to me to be much simpler than anything that has been done so far. The theory which he gives us ought to prove of great practical utility by reason of its simplicity. Of course, the whole problem is dealt with for ideal conditions only. That is, there is no magnetic leakage, there is no hysteresis, there are no Foncault currents; so that all the numerical results obtainable from the author's theory will be modified to a greater or less extent by these three everpresent imperfections, and will have to be allowed for by the designer.

Of course a great many people will say, what is the use of a theory which simply treats of an ideal case that never presents itself in practice? They said the same thing when the theory of 
the alternating current transformer was brought forward to the notice of practical engineers. They called it the "phantom theory" of a "phantom transformer," implying often by that name that the theory had little or no practical value. And yet somehow or other, when the relations, obtained for purely ideal conditions, were compared with actual experimental tests, it was found that they agreed pretty well with them. Of course those men who had always had a grudge against "iron-less" mathematics and against the so-called text-book mathematicians and text-book physics, and against all electrical discussions which did not smell of the shop, when they found that the phantom equations agreed well with the practical results, were quite surprised and did not understand the "miracle." For instance, I do not know that I ought to touch upon this much discussed point: some people had a great deal of mistrust against the supposition that impressed E. M. F., produced by most alternators can be treated as a pure sine. It was not a pure sine, and therefore all results obtained on the hypothesis just mentioned were of no use. The curve was not exactly a pure sine, but quite often nearly so. Practical results, however, agreed with the theory, because a distorted electromotive force utilizes its fundamental component only when it works an iron core closed magnetic circuit transformer, and when the transformer load is not too small. This is especially true of old frequencies like the Westinghouse frequency. There is something new; something that we ought to inquire into, and inquiring, we shall undoubtedly find, new properties of an iron core closed magnetic circuit. ${ }^{1}$ So in the case of this ideal theory of the induction motor, although its results may differ considerably from the actual facts, it can be safely accepted as a first approximation to actual truth as a first guide. Then, if there should be differences between the ideal and the practical conditions, as there certainly will be, we will be able to measure these differences, to inquire into the intensity of the causes producing them, and in that way obtain more definite knowledge of all the activities which are concerned in this particular machine, the induction motor.

Mr. Steinmetz:-I have read Lieut Reber's valuable paper and was very much interested in it, and when in the following I shall take rather a critical view of it, I beg you to understand that I do not depreciate the value and importance of the paper, but after Dr. Pupin has shown us the good features of the paper, I shall now endeavor to designate its weak points.

First, with regard to the neglect of hysteresis in the paper, I may say that in induction motors, and especially smaller ones, the hysteretic loss is one of the largest of all the losses, and thus should not be neglected in a complete theory.

1. For fuller information see M. I. Pupin: "Resonance Analysis of Alternating. Currents, etc.", Transactions, p. 528. 
I may further draw the attention to the raggedness of the curves given in the paper, and state that this is not inherent to the theory, but merely due to the fact that the curves were plotted from tables calculated to two decimals only. The neglect of the third decimal becomes noticeable in the curve.

On page 737 , it is stated that the motor should not be pushed to a point more than half the maximum torque. This general statement I consider wrong. Let us rather say that at full load the motor must have sufficient margin of torque to carry it over any overload, which it may possibly be exposed to in practical operation. How much this is, greatly depends upon the circumstances; in a motor driving a ventilating fan, it is entirely useless to allow such a large margin, since such a motor by the nature of its load cannot be overloaded. On the other hand, a railway motor allowing 100 per cent. margin over its rated torque could never work satisfactorily, but 500 or even 1000 per cent. margin would come nearer the requirements. In general, in most cases of practical application, 100 per cent. margin is too much and 50 per cent. quite enough. The same applies to the starting torque. Thus 1 have all the standard induction motors designed to give a starting torque and maximum torque 50 to 60 per cent. in excess of the running torque, while wherever more or less is desired, the motor is considered as special.

With regard to the effect of the frequency, I would like to dis a cuss somewhat more a statement on the last page. As it is worded there, though correct, it may be greatly misleading. It is: "Increasing the frequency $n$ times in a motor without a con"denser, the velocity will be increased $n$ times, $K_{\text {。 }}$ decreased $n$ " times, the maximum torque is not affected, while the hysteresis is "increased $n$ times nearly, the output of the motor will be in"creased nearly $n$ times, if the motor is run at a given percentage " of the maximum torque. Hence it is an advantage to increase "the frequency till the hysteresis heating becomes too great or the " "motor runs too fast." And then it is stated further along, "A "high frequency motor will weigh less than a low frequency one." This is not the case. Instead of "a high frequency motor." it. should be said "a high speed motor." The quantity which is decided upon and determined first in a motor, is its speed. If now you take a motor running first at one frequency and then run it at twice the frequency but the same speed, by doubling. the number of poles, you tind in general, the opposite true. Then the high frequency motor is less favorable. So in a motor with a given number of poles, the gain by increasing the frequency is merely due to the increase of speed, and if a motor. is improved by doubling the frequency and doubling the speed, it is still more improved by doubling the speed but retaining the same frequency, by halving the number of poles.

The main objection, however, which I have against the paper is that it is by far too mathematical. Mathematics is a very nice 
thing indeed, and the most powerful weapon science has, and having done a little work myself in mathematics, pure and applied, I may be allowed to say that pure mathematics may go as high as desired in purely scientific interests, but if you apply mathematics to an engineering problem, then it is proper to ask; what is the use of the results? or, can we make any application of it for engineering practice?

There are two ways of solving an engineering problem by theory; either by forcing a solution by bringing the whole power of analysis to bear upon it, or to arrive at the solution by a simple way, by a short cut, we may say.

Now taking the present paper: In the equations here, the quantity, $K$, appears several times. This quantity $K$ is defined on page 737. It is a quotient whose terms are differences of quotients. so you see that the expression, if you substitute backwards to the orig nal constants, will be so complicated that it is hardly possible to make any use of it.

And now coming back to this quantity, $L$, the coefficient of self-induction. Even this is not a simple quantity, because it contains two entirely heterogeneous terms. $L$ is here used in the sense used in former times in theoretical investigations, as referring to the number of interlinkages of the circuit with the flux produced by the circuit. In the primary circuit, the current will set up a magnetic field which will pass around the circuit with a given number of interlinkages, and the total product, for unit current, of the number of interlinkages into the number of turns is the coefficient of self-induction. Now this product has two heterogeneous effects; a part of the flux passes around the primary coil without passing around the secondary coil. This chokes off the electromotive force and reduces the output of the motor. The other part passes around the primary coil and around the secondary coil, and does the work. You see, consequently, that no conclusions can be drawn from the quantity, $L$, because it contains two terms, one representing the work done, and the other choking or reducing the work. Therefore, where the quantity, $L$, enters, you cannot separate the useful part. You cannot draw any conclusions how to design a motor from the equations where $L$ enters.

Dr. PupIn:-There is no leakage, and, therefore, you are stepping beyond the limits of the paper.

Mr. Steinmetz:-Then I take back what I said beyond the limits, but keep to my first objection that the method is too. theoretical and too limited.

It assumes no magnetic leakage. Now the maximum output of an induction motor is essentially determined by the magnetic leakage or self-induction, while resistance plays a lesser part. Conseqently by neglecting the magnetic leakage, the paper neglects the principal factor, which determines the maximum output of the motor. 
However, I do not know whether the magnetic leakage is really excluded in the paper, because-

Dr. Pupin:- If you will look at the beginning of the paper, you will find that it so states in the sixth line.

Mr. Steinmetz:- If there is no magnetic leakage the product of the two $L$ 's is equal to the $M^{2}$. I think I saw a statement here that it may be equal or larger. In this case this objection does not hold.

However, by separating the $L$ in these two parts, representing the useful flux and the flux of self-induction, or rather in this case, I would say by introducing a second quantity, $L^{1}$, as the magnetic leakage, you can make the equation more complete.

Now, I have made the statement that the paper appears to me too mathematical. The induction motor is such a simple apparatus, just as simple as the alternating current transformer, that it should be assumed a priori that the theory of the induction motor should be much simpler. Moreover, I think the theory of the induction motor ought to include the hysteresis, and ought to include the stray field of magnetic leakage. because the hysteresis is the largest factor in efficiency, and the leakage is the limiting factor in the output. The theory ought to make no assumption as to how many phases there are, and if you will allow me, I will make a few sketches explaining that. I do not intend to make use of anything more mathematical than Ohm's law, and the equation that the power is the electromotive force times current. But I will use complex quantities, which, I assume, are now generally known.

\section{Theory of the Induction Motor.}

In the following sketch of a theory of the induction motor, no further assumptions shall be made but Ohm's law and the power equation :

$$
P=E C \text {. }
$$

The theory will be general, that is, independent of the number of phases in field and in armature, etc., and shall include, and not neglect, the effect of hysteresis, magnetizing current, of selfinduction or magnetic stray field, etc.

The method of complex quantities shall be used, however, which, I presume, can be considered now as universally known and understood.

Capitals shall denote complex or vector quantities, small letters represent absolute values.

Let, in an induction motor,

$\bar{Y}=$ primary admittance, per circuit, ${ }^{1}$

1. $Y=\rho+j \sigma$ is the ratio of total exciting current, or current at no load or synchronism, to the E. M. F., $\rho$ its power component, $\sigma$ its reactive component. Thus: 
$U=$ primary impedance, ${ }^{1}$

$U_{1}=r_{1}-j k s_{1}=$ secondary impedance, where:

$k=$ slip, or ratio of secondary frequency to main frequency, ${ }^{2}$

$a=$ ratio of secondary turns to primary turns (ratio of transformation).

Since the reactive component of secondary impedance depends upon the slip, $k$, the two components of secondary impedance have been introduced:

where:

$$
U_{1}=r_{1}-j k s_{1}
$$

$s_{1}=2 \pi N L_{1}=$ secondary reactance at rest, or full frequency.

Counting the time from the moment where the mutual magnetic flux, or useful magnetism (flux interlinked with both, primary and secondary circuit) passes through zero, the magnetic flux is denoted by :

$$
M=j m \text {. }
$$

Thus the E. м. F. induced by this flux in the primary circuit is:

$$
E=-e \text {, }
$$

where $e$ is the "counter E. M. F. of the motor."

The e. M. F. induced in the secondary circuit is :

$$
E_{1}=-a k e,
$$

since the secondary circuit cuts the same flux, $m$, at the lower frequency, $k N$.

Hence the secondary current is :

$$
\begin{gathered}
C_{1}=\frac{E_{1}}{U_{1}}=-\frac{a k e}{r_{1}-j k s_{1}} . \\
\rho=\frac{\frac{\text { hysteretic energy current }}{\text { E. M. F. }},}{\sigma=} \\
v=\frac{\text { magnetizing current }}{\text { E. M. F. }}, \\
\sqrt{\rho^{2}+\sigma^{2}}=\frac{\text { total exciting current }}{\text { E. M. F. }},
\end{gathered}
$$

$\rho$ and $\sigma$ are calculated from dimensions and material of the motor, and determined experimentally by ammeter and wattmeter readings at no load.

1. $U=r-j s$, where $r=$ (equivalent) resistance, $s=2 \pi N L=$ reactance of primary circuit, the latter referring, however, to the magnetic flux of selfinduction, or stray magnetism, only, that is the flux produced by the primary circuit and interlinked with the primary circuit only, but not with the secondary circuit. Thus $s$ does not include the mutual inductance, or the useful magnetism, $M$. The same applies to $U_{1}$.

$r$ and $s$ are calculated from the dimensions of the motor and observed experimentally by ammeter and wattmeter readings at standstill with short-circuited armature.

2. $k=0$ at synchronism,

$k=1$ at standstill,

$k N=$ frequency of armature current 
Hereto corresponds in the primary circuit the current :

$$
\begin{aligned}
C_{1}^{1} & =-a C_{1} \\
& =\frac{a^{2} k e}{r_{1}-j k s_{1}} .
\end{aligned}
$$

The primary exciting current is:

$$
C_{0}=Y e
$$

Hence the total primary current:

or, substituted:

$$
C=C_{0}+C_{1}^{1}
$$

Primary Current:

$$
C=e\left\{Y+\frac{a^{2} k}{r_{1}-j k s_{1}}\right\} .
$$

The E. M. F. consumed by the primary impedance is :

$$
\begin{aligned}
E^{1} & =C U \\
& =e U\left\{Y+\frac{a^{2} k}{r_{1}-j k s_{1}}\right\} .
\end{aligned}
$$

Thus the total primary impressed E. M. F. is :

or, substituted:

$$
E_{0}=E_{1}+e
$$

Primary Impressed E. M. F.:

$$
E_{\theta}=e\left\{1+U Y+\frac{a^{2} k U}{r_{1}-j k s_{1}}\right\} .
$$

The power transmitted into the secondary circuit is:

$$
E C_{1}^{1}=e a C_{1} \text {. }
$$

The power wasted by the secondary current is:

$$
E_{1} C_{1}=\text { k e a } C_{1}
$$

hence, the output, or the net power of the motor is :

$$
\begin{aligned}
P & =E C_{1}^{1}-E_{1} C_{1} \\
& =e a C_{1}(1-k)
\end{aligned}
$$

or, substituted :

$$
P=\frac{e^{2} \alpha^{2} k(1-k)}{r_{1}-j k s_{1}},
$$

and rationalized :

Power :

$$
P=\frac{e^{2} a^{2} k(1-k) r_{1}}{r_{1}^{2}+k^{2} s_{1}^{2}}
$$


The torque of the motor is :

$$
T=\frac{b P}{1-k},
$$

where $b$ is a constant depending upon frequency, $N$, and number of poles, $p$ :

$$
b=\frac{550}{.746 \pi p N} \text { in pounds at } 1 \text { foot radius. }
$$

Substituting $P$ gives:

Torque :

$$
T=\frac{b e^{2} a^{2} k r_{1}}{r_{1}^{2}+k^{2} s_{1}^{2}}
$$

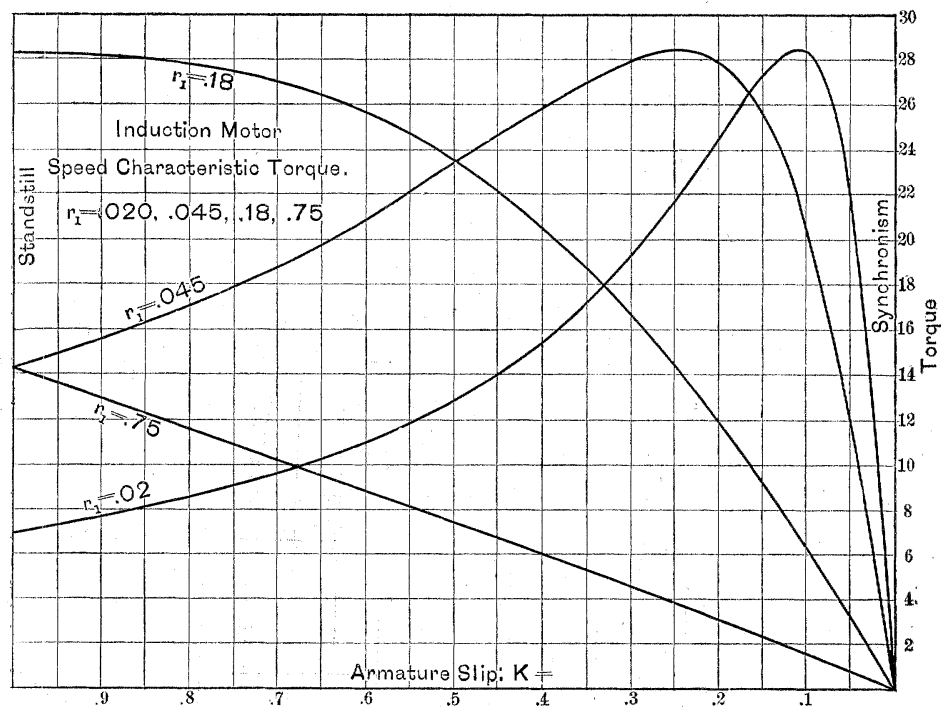

FIg. 5.

These four equations are the fundamental equations of the in. duction motor, giving current, impressed E. M. F., power and torque as functions of the slip, $k$, and the counter E. м. F., $e$.

Thus, at constant impressed E. M. F., $E_{0}$, we eliminate $e$ by equation (2), and get from equations (1), (3), (4) the current, power and torque, as functions of the slip, $k$, that is the speed, and eliminating again $k$ by equation (1), equations (3) and (4) give power and torque as functions of the primary current, at constant impressed E. M. F. In general, it is preferable, however, to retain $k$ and $e$ as parameters.

The armature resistance, $r_{1}$, appears explicit in the equations, so that the effect of a change of $r_{1}$ can directly be seen from the equations. 
Substituting :

$$
k=0,
$$

gives the condition of synchronous running, or of no load:

$$
\begin{aligned}
& C=e Y \\
& E_{0}=e(1+U Y), \\
& P=0, \\
& T=0 .
\end{aligned}
$$

Substituting :

$$
k=1
$$

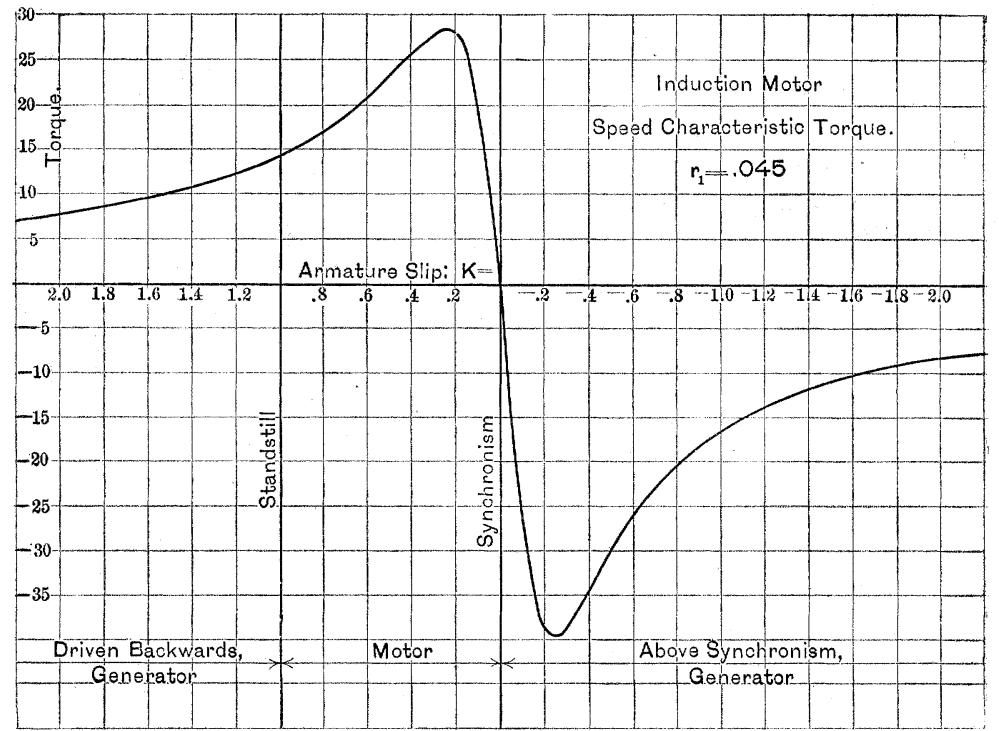

Fig. 6.

gives the conditions in starting, or at rest:

$$
\begin{aligned}
C & =e\left\{Y+\frac{a^{2}}{r_{1}-j s_{1}}\right\} \\
E_{0} & =e\left\{1+U Y+\frac{U a^{2}}{r_{1}-j s_{1}}\right\} \\
P & =0 \\
T_{0} & =\frac{b e^{2} a^{2} r_{1}}{r_{1}^{2}+s_{1}^{2}} \\
\frac{d T_{0}}{d \cdot r_{1}} & =0
\end{aligned}
$$

gives the armature resistance, $r_{1}$, which gives maximum starting torque. 
Substituting :

$$
k<0
$$

gives the conditions of running above synchronism :

$$
\begin{aligned}
& P<0 \\
& T<0 ;
\end{aligned}
$$

that is, the machine gives a backwards torque and consumes power, that is, its primary circuit acts as electric generator.

$$
k>1
$$

gives the conditions of backwards running:

$$
\begin{aligned}
& P<0 \\
& T>0 ;
\end{aligned}
$$

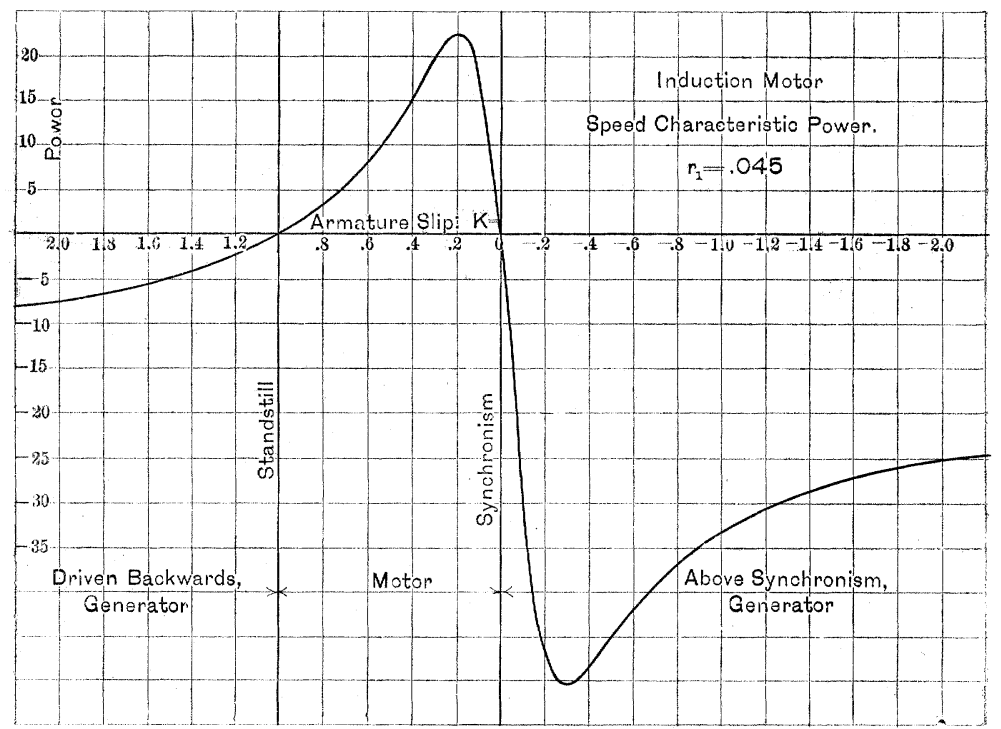

FiG. 7.

that is, the power is negative, the torque positive, that is now against the direction of rotation, and the machine consumes power, and its secondary circuit acts as electric generator.

gives the maximum power,

$$
\frac{d P}{d k}=0,
$$

$$
\frac{d T}{d k}=0,
$$

gives the maximum torque of the motor.

From the four fundamental equations the behavior of the induction motor under all conditions of load, etc., can be calculated and plotted in curves. 
The values of equations (3) and (4) refer to one circuit only. Thus the total power (resp. torque) of the induction motor is $=3 P$ in a three-phase, $=2 P$ in a quarter-phase, and $=P$ in a monocyclic induction motor.

The general shape of such motor characteristics is shown in Figs. 5, 6, 7, which give the torque and the power of a threephase motor, at various armature resistances: $r_{1}=.02 ; .045$; $.18 ; .75$ ohms, as function of the speed, that is, the slip, $k$, with the constants :

$$
\begin{aligned}
& Y=\rho+j \sigma=.03+.2 j, \\
& U=r-j s=.03-.1 j, \\
& U_{1}=r_{1}-j k s_{1}=r_{1}-.08 k j, \\
& a=1,
\end{aligned}
$$

110 volts between the lines, hence

$$
E_{0}=63.5 \text {. }
$$

There you have all the quantities. No assumptions are made whether it is a three-phase, single-phase, or any other induction motor. I do not make any assumption either how the armature is wound.

Mr. A. E. Kennelly:-Mr. President and Gentlemen: I think that after what Mr. Steinmetz has told us concerning the advisability of having the paper before us include the question of hysteresis and other losses, we ought to feel very grateful to the author for having left them out, because to what extent the paper would have run, had those more difficult questions been included, it is difficult to say. But I, for one, am opposed to other than engineering methods for treating engineering subjects. I believe that the method which has just been discussed by Mr. Steinmetz before us on the blackboard is far more capable of giving us the engineering properties of induction motors than are the methods based on Maxwell's equations. When we consider the work done in lifting a weight from the ground, it is not necessary to start with Newton's second law of motion. Similarly when we move a dynamo, we need not start with Maxwell's electro-kinetic momentum of a circuit. These things are true and beautiful, but we need not always be bringing them into print. The difficulties in the problem that confront the engineer are sufficiently great without adding to them analytical difficulties in dealing with the subject. I think the paper might have been shortened and its utility to engineers greatly enhanced if many of the difficulties which enshroud that subject had been cleared away and a simple exposition given to us. 